\title{
AS REPRESENTAÇ̃̃ES SOCIAIS DOS LICENCIANDOS EM CIÊNCIAS BIOLÓGICAS SOBRE O SER BIÓLOGO E O SER PROFESSOR
}

\begin{abstract}
RESUMO: O artigo analisa as Representações Sociais (RS) construídas no cotidiano da formação inicial dos licenciandos em Ciências Biológicas. As informações derivam de questionário aplicado aos alunos do $1^{\circ}$ ao $4^{\circ}$ ano $(n=138) \mathrm{em} 2010$. Os dados coletados foram processados pelos softwares Evoc e Simi. Os conceitos de habitus, proposto por Bourdieu, de RS, por Moscovici, e núcleo central das RS, por Abric, subsidiam a análise. O núcleo central da RS de biólogo mostrou-se homogêneo em torno do elemento pesquisador. A representação de professor, mais abstrata e heterogênea, se estrutura em torno dos elementos educador e conbecimento. A docência manifestou-se como construção arraigada na trajetória escolar e na área de conhecimento sem alterar-se significativamente durante a formação inicial.
\end{abstract}

Palavras-chave: Formação de professores. Representações Sociais. Ciências e Biologia.

\section{SOCIAL REPRESENTATIONS OF UNDERGRADUATES IN BIOLOGICAL SCIENCES ABOUT BEING A BIOLOGIST AND BEING A TEACHER}

ABSTRACT: The paper analyzes the Social Representations (SR) built on everyday routineof undergraduate courses in Biological Sciences. Data were gathered by applying a questionnaire to students from the $1^{\text {st }}$ to the $4^{\text {th }}$ grade $(n=138)$ in 2010 . The database was then processed by the softwares EVOC and SIMI. The concepts of habitus, proposed by Bourdieu, of SR, by Moscovici and the central nuclei of SR, by Abric, come as a base to support the present analysis. The central nuclei of the SR of a biologist has been seen as homogeneous around the element researcher. On the other hand, a SR of a teacher has revealed itself as something more abstract and heterogeneous, it is structured around the elements educator and knowledge. Teaching is perceived as a construction rooted in the schooling trajectory and in the knowledge area without significant changes throughout pre-service teacher education.

Keywords: Teaching Education. Social Representations. Sciences and Biology.

\section{Patricia Caldeira Tolentino * \\ Ademir José Rosso **}

\footnotetext{
* Doutoranda em Educação Científica Tecnológica na Universidade Federal de Santa Catarina. Email: pctolentino@uepg.br

* * Doutor em Educação pela Universidade Federal de Santa Catarina. Professor da Licenciatura em Biologia e do Programa de Pós-Graduação em Educação da Universidade Estadual de Ponta Grossa. Email: ajrosso@uepg.br
} 


\section{INTRODUÇÃO}

A formação acadêmica nos cursos de licenciatura é o lócus da organização do conhecimento de base para a docência. Seu processo compreende, de um lado, as observações, as vivências e as experiências empreendidas nesse espaço social; e, de outro, os enquadramentos culturais e teórico-metodológicos que vão sendo adquiridos e redimensionados pelos licenciandos durante a sua trajetória formativa. Esses elementos do processo de desenvolvimento pessoal e profissional formam as representações mobilizadas durante a constituição da identidade docente.

A produção acadêmica sobre formação de professores no Brasil tem discutido, reiteradamente, os problemas que envolvem o seu contexto (CANDAU, 1987; GATTI, 1992, 2000; LUDKE, 1994; PIMENTA, 1994; BRZEZINSKI, 1996; DINIZ-PEREIRA, 1999; MELLO, 2000; SAVIANI, 2009). Nas licenciaturas específicas em determinado campo de estudo, os problemas se acentuam no que se refere à dicotomia teoria e prática (CANDAU; LELIS, 1999; CANDAU, 1997) e às disciplinas de conteúdo e às disciplinas pedagógicas (CARVALHO; VIANNA, 1988; DINIZ-PEREIRA, 2000). Quando se trata das licenciaturas formadoras do professor de ciências, vários estudos apontam as dificuldades na formação docente nessa área de conhecimento (FREITAS; VILLANI, 2002; VILLANI; PACCA; FREITAS, 2002; CARVALHO; GIL-PÉREZ, 2006). De acordo com recente estudo, Gatti (2010) aponta que as licenciaturas em Ciências Biológicas dedicam um grande percentual de sua carga horária para as disciplinas de conteúdo disciplinar, em detrimento de um eixo formativo definido para a docência. Com isso, a imagem do professor nessas licenciaturas é secundária, em função da idealização do pesquisador das subáreas da biologia (BRANDO; CALDEIRA, 2009). Essa dicotomia conteúdo/forma da área das ciências naturais, que prioriza os conteúdos específicos sobre os pedagógicos, dificulta que se pense a licenciatura numa totalidade (ROSSO, 2007).

Nesse sentido, problematiza-se: os processos que atuam na estruturação sociocognitiva da realidade e as características do meio social e ideológico interferem nas representações construídas pelos licenciandos?

Partindo dessa questão, o presente trabalho tem como objetivo explicitar quais representações sobre professor e biólogo estão em evidência entre licenciandos em Ciências Biológicas. Pretende abordar, a partir da formação inicial do professor de ciências e biologia, as influências subjetivas e objetivas desse contexto social, dirigindo o olhar ao cotidiano de um curso de licenciatura que tem como papel principal orientar a formação de seus estudantes e direcionar seus interesses profissionais, favorecendo a constituição das bases identitárias da docência.

O curso estudado possui as habilitações bacharelado e licenciatura ofertadas em paralelo, apesar da organização curricular, que busca a autonomia das licenciaturas (BRASIL, 2002). Entretanto, deve-se considerar que, diante do proposto pela legislação, a reelaboração curricular das licenciaturas e a prática do cotidiano do curso podem apresentar distorções. A orientação das Diretrizes Curriculares 
Nacionais (DCN), que fortalece uma dimensão prática do processo de formação, empobrece o papel do conhecimento científico de referência (ANDRADE et al., 2004). Essa orientação curricular se contrapõe às visões formativas que norteiam as ações dos docentes de disciplinas de conteúdo específico que atuam nas licenciaturas, pois eles também são responsáveis pela formação de pesquisadores de sua área.

Os conceitos de habitus, proposto por Pierre Bourdieu (1997, 1999, 2003, 2009), e de representação social, correspondente às teorias de Serge Moscovici (2003) e de Abric (2000), apresentam-se como elementos centrais no presente trabalho. As explicações da psicologia social devem, necessariamente, ser completadas por explicações sociológicas, colaborando assim para uma melhor contribuição dos jogos societais (DOISE, 2002). Esses pressupostos teóricos alimentam o entendimento do processo de constituição da identidade profissional na formação inicial, pois envolvem um decurso que vai além do indivíduo, considerando em sua personificação o contexto sociocultural.

Nesse sentido, "a construção da identidade se faz no interior de contextos sociais que determinam a posição dos agentes e por isso mesmo orientam suas representações e suas escolhas" (CUCHE, 2002, p. 182). Igualmente, a constituição da identidade "é um fenômeno que deriva da dialética entre um indivíduo e a sociedade” (BERGER; LUCKMANN, 2004, p. 230). Uma vez cristalizada, essa constituição "é mantida, modificada ou mesmo remodelada pelas relações sociais" (BERGER; LUCKMANN, 2004, p. 228). A especificidade de formação da identidade pessoal e grupal dos indivíduos pode ser considerada a partir do conceito de habitus discutido por Bourdieu (2000, citado por SETTON, 2009). Assim, parte-se dessas premissas gerais para se explicitar a gênese desse processo.

O habitus mantém uma cumplicidade ontológica com o mundo social que o produz, procedente de um conhecimento sem consciência, esclarecendo que são disposições adquiridas, socialmente constituídas (BOURDIEU, 1999). Tais disposições são adquiridas por aprendizagem implícita ou explícita, funcionando como esquemas geradores de estratégias, conforme os interesses objetivos dos seus autores, sem terem sidos gerados para esse fim (BOURDIEU, 2003). Os indivíduos são agentes atuantes, dotados de um senso prático proveniente do sistema de preferências, resultante da incorporação das estruturas que guiam a percepção objetiva (BOURDIEU, 1997). O habitus, como produto histórico, é tanto individual quanto coletivo, sendo considerado um meio de ação que permite a criação ou o desenvolvimento de estratégias individuais ou coletivas. Todavia, o habitus individual reflete a classe, como produto da homogeneidade das condições objetivas de existência. As práticas individuais e coletivas apresentam regularidade e continuidade, conforme os esquemas engendrados pela própria história (BOURDIEU, 2003, 2009).

A Teoria das Representações Sociais foi desenvolvida, segundo Moscovici (2003), sob o seguinte pano de fundo: “a primazia das representações ou crenças, a origem social das percepções e das crenças e o papel, algumas vezes de coação, dessas representações e crenças" (MOSCOVICI, 2003, p. 176). Como forma de conhecimento prático, as representações sociais estão implantadas entre as 
correntes que analisam o conhecimento do senso comum, falseando o estatuto da objetividade e da busca da verdade e rompendo, assim, com a ciência-verdade e o senso comum-ilusão. Trata-se de uma amplitude do olhar ao ver o senso comum como conhecimento legítimo e propulsor de transformações sociais (SPINK, 1995).

A representação social apresenta-se como uma visão de mundo em que não há distinção entre sujeito e objeto. O objeto está presente no contexto, que é concebido pelo indivíduo ou pelo grupo de alguma maneira, enquanto prolongamento de suas atitudes e de seu comportamento (ABRIC, 2000). De acordo com Jodelet (2001), as representações são guias nas definições dos diferentes aspectos da realidade, fazendo com que sejam interpretados e posicionando os objetos à frente dos sujeitos por meio de um ato de pensamento segundo o qual o sujeito relaciona-se com o objeto. A abordagem das representações sociais acompanha produto e processo da atividade de adequação da realidade exterior ao pensamento e à organização psicológica e social dessa realidade.

Toda realidade é representada, ou seja, reapropriada e reconstruída pelo sistema cognitivo do indivíduo ou do grupo, em que se integra com os seus sistemas de valores, os quais dependem de sua história e dos contextos que o cercam. A representação, como visão funcional do mundo, permite ao indivíduo ou ao grupo atribuir um sentido às condutas e compreender a realidade a partir do seu sistema de referências. Isso permite ao indivíduo a adaptação e o encontro de seu lugar nessa realidade, não como um simples reflexo, mas como uma organização significante, um guia para a ação, orientando as ações e as relações sociais (ABRIC, 2000).

Como um dos desdobramentos da Teoria das Representações Sociais, a abordagem estrutural concentra sua atenção em representações estabilizadas (DESCHAMPS; MOLINER, 2009). Moscovici (2003), ao tratar de tal hipótese, considera que a representação social é composta por "elementos cognitivos, ou esquemas estáveis, ao redor dos quais estão ordenados outros elementos cognitivos, ou esquemas periféricos" (MOSCOVICI, 2003, p. 219). Esses esquemas estáveis, denominados de núcleo central, são determinados pela natureza do objeto representado e pelo tipo de relações mantidas com esse objeto, apontando, assim, "sistema de valores e normas sociais que constituem o meio ambiente ideológico do momento e do grupo” (ABRIC, 2000, p. 31).

O núcleo central é o elemento mais estável da representação. Sua delimitação é essencialmente social e ligada às condições históricas, sociológicas e ideológicas, associando-se diretamente a valores e normas dos indivíduos e dos grupos. Entretanto, não é a presença concreta de um determinado elemento que define sua centralidade, mas, sim, o fato que dá sentido à representação, pois se pode identificar quantitativamente mais que um elemento central nos discursos dos sujeitos, embora um possa ser central, e outro, não (ABRIC, 2000).

É por meio dos elementos periféricos que as representações aparecem no cotidiano, sendo o funcionamento do núcleo central compreendido como uma dialética contínua com a periferia (FLAMENT, 1994 citado por ALVES-MAZZOTTI, 2007). "Se o sistema central é normativo, o sistema periférico é funcional; quer dizer 
que é graças a ele que a representação pode se ancorar na realidade do momento" (ABRIC, 1993, citado por SÁ, 1996). Para Abric (2000), os elementos periféricos são procedentes da ancoragem da representação com a realidade, apresentando a interface entre o núcleo central e a situação concreta na qual a representação é trabalhada. As informações novas são integradas à periferia da representação, por isso seus elementos constituem os aspectos móveis e evolutivos da representação. Essa flexibilidade do sistema periférico permite a defesa da centralidade da representação, pois a possível transformação de uma representação se processa por meio da transformação dos seus elementos periféricos, e não dos centrais.

A articulação conceitual do habitus com a representação social considera não apenas os sujeitos da representação, mas também o meio social em que transitam, permitindo discutir com maior propriedade as condições objetivas dos produtores das representações. "A particularidade do estudo das representações sociais é o fato de integrar na análise desses processos a pertença e participação, sociais ou culturais, do sujeito" (JODELET, 2001, p. 27). O trabalho de Bourdieu (1997, 2008, 2009) pressupõe a estrutura social objetiva que engendra as disposições incorporadas nas experiências e nas práticas cotidianas. A noção de habitus como sistema de disposições duráveis predispostas a funcionar como estruturas estruturantes (BOURDIEU, 2003), associada às representações sociais, ultrapassa a especificidade individual que é transmitida pelo informante no momento da pesquisa, inserindo-o na estrutura dos espaços sociais dos quais ele faz parte.

De acordo com Bonnewitz (2003, p. 76), “a socialização corresponde ao conjunto dos mecanismos pelos quais os indivíduos realizam a aprendizagem das relações sociais entre os homens e assimilam as normas, valores e crenças de uma sociedade ou de uma coletividade". Por isso, as representações sociais "são sempre complexas e necessariamente inscritas dentro de um referencial de um pensamento preexistente, sempre dependentes, por conseguinte, de mudanças e crenças ancoradas em valores, tradições e imagens do mundo e da existência" (MOSCOVICI, 2003 p. 216).

A partir desse quadro apresentado, entende-se que o espaço social onde os licenciandos em Ciências Biológicas estão inseridos contribui significativamente para a compreensão das estruturas a que esses sujeitos estão submetidos e para o reconhecimento da influência das disposições adquiridas nas práticas desenvolvidas durante o processo formativo para a docência, processo este que fundamenta a constituição da identidade profissional. A utilização das representações sociais proporciona um quadro de análise e interpretação que permite compreender a interação do indivíduo com o contexto social. O habitus, princípio gerador das práticas, é importante instrumento para análise das atitudes que estruturam as representações e geram as práticas do cotidiano do curso. Assim, a partir das representações dos licenciandos, supõe-se entender os processos que atuam na estruturação sociocognitiva da realidade e as características do meio social e ideológico. 


\section{METODOLOGIA}

Este artigo é oriundo de uma pesquisa (TOLENTINO, 2010) que teve como objetivo a análise das representações de professor e biólogo ${ }^{1}$ pelos acadêmicos do curso de Licenciatura em Ciências Biológicas de uma universidade pública do interior do Paraná. Empregando elementos da Teoria das Representações Sociais (ABRIC, 2000; MOSCOVICI, 2003) no enfoque estrutural do estudo, buscou-se identificar e explicitar as representações geradas pelos licenciandos. O universo da pesquisa, correspondente ao ano de 2010, foi composto por 138 acadêmicos do $1^{\circ}$ ao $4^{\circ}$ ano do curso, de um total de 158 alunos, dos turnos vespertino e noturno. Os licenciandos participaram do estudo após a ciência da pesquisa e a assinatura do termo de consentimento livre e esclarecido. Os dados foram coletados por meio de um questionário composto de duas partes: a primeira parte consiste em uma Associação Livre de Palavras (ALP); e a segunda contém questões fechadas e abertas. Apresentam-se neste trabalho as análises decorrentes da primeira parte do questionário, vinculada à associação livre de palavras (ALP), em que se pretende tecer considerações sobre o sentido da formação de professores de ciências e biologia.

A técnica da ALP é bem difundida em pesquisas que utilizam o aporte teórico e metodológico das representações sociais, pois possibilita o acesso aos conteúdos nucleares, periféricos e latentes (ACOSTA et al., 2007). Essa técnica consiste em solicitar a cada respondente que, a partir de um termo indutor, descreva por palavras ou expressões aquilo que se apresenta à sua mente naquele momento. Abric (1993), citado por Sá (1996), considera a técnica ideal para coleta dos elementos constitutivos que contêm uma representação.

A partir das expressões indutoras "professor é" e "biólogo é", os licenciandos foram solicitados a escrever, na primeira parte do questionário, de cinco a oito palavras relacionadas a essas expressões. Juntamente com as questões, solicitou-se que cada sujeito numerasse as palavras de acordo com seu nível de relevância e que justificasse a escolha do elemento mais relevante. Com isso, possibilitou-se um processo reflexivo da importância do principal elemento da representação social.

As informações coletadas foram submetidas a processamento pelo software Ensemble de programmes permettant l'analyse des evocations (Evoc), um conjunto de programas elaborado por Pierre Vergés que analisa as evocações buscando seus elementos centrais e periféricos. Os relatórios fornecidos pelo software favorecem o reconhecimento da estrutura das representações sociais por meio da construção de um quadro com os elementos estruturais. Para se obter a ligação entre os elementos constituintes da representação social, utilizou-se o software Simi. Esse procedimento de análise resulta em uma árvore máxima que ilustra o cruzamento entre todos os termos da representação que possuem algum tipo de relação entre si, com indicações do número de sujeitos que associam da mesma maneira os respectivos elementos. 


\section{Análise das evocações à expressão indutora "biólogo é"}

Após o refinamento das informações, a associação ao significado da expressão "biólogo é" produziu, nos 138 licenciandos participantes do estudo, um total de 711 palavras, das quais 84 são diferentes. Para a composição dos elementos estruturais, foram desprezadas as evocações cuja frequência foi inferior a sete (menor do que 5\% dos informantes), o que resultou em descarte de $17,9 \%$ e aproveitamento de $82,1 \%$. A constituição dos valores para a composição do núcleo central e de elementos periféricos foi extraída de relatório Rangmot emitido pelo software: frequência mínima $=7$, frequência intermediária $=19$ e Ordem Média das Evocações $(\mathrm{OME})=3,2$.

Ilustra-se, a seguir, a organização dos elementos oriundos das evocações:

Figura 1: Distribuição dos elementos da representação social de "biólogo" Fonte: Tolentino (2010, p. 66-67), parcialmente modificada.

\begin{tabular}{|c|c|c|c|c|c|}
\hline \multicolumn{3}{|c|}{ Núcleo central } & \multicolumn{3}{|c|}{ Elementos intermediários } \\
\hline \multicolumn{3}{|c|}{ Frequência $>=19,0 M E<3,2$} & \multicolumn{3}{|c|}{ Frequência $>=19, \mathrm{OME}>3,2$} \\
\hline Palavras & Freq. & OME & Palavras & Freq. & OME \\
\hline Pesquisador & 105 & 2,28 & Conhecimento & 27 & 3,22 \\
\hline Conscientização & 33 & 2,97 & Natureza & 25 & 3,28 \\
\hline Curiosidade & 30 & 3,17 & Educador & 21 & 3,71 \\
\hline Vida & 29 & 2,93 & - & - & - \\
\hline Preservação & 25 & 2,48 & - & - & - \\
\hline Amor & 22 & 2,91 & - & - & - \\
\hline Compromisso & 20 & 2,80 & - & - & - \\
\hline Dedicação & 19 & 3,11 & - & - & - \\
\hline \multicolumn{3}{|c|}{ Elementos intermediários } & \multicolumn{3}{|c|}{ Periferia } \\
\hline \multicolumn{3}{|c|}{ Freq. $<19, \mathrm{OME}<3,2$} & \multicolumn{3}{|c|}{ Freq. $\langle 19, \mathrm{OME}\rangle=3,2$} \\
\hline Palavras & Freq. & OME & Palavras & Freq. & OME \\
\hline Observador & 18 & 3,00 & Professor & 18 & 3,78 \\
\hline Ambiente & 17 & 2,82 & Ativista & 16 & 3,25 \\
\hline Profissional & 12 & 2,92 & Estudo & 16 & 3,25 \\
\hline Aprendizagem & 11 & 3,18 & Descobridor & 15 & 3,60 \\
\hline Humano & 10 & 2,40 & Metódico & 14 & 3,43 \\
\hline Idealista & 9 & 2,56 & Alternativo & 10 & 3,90 \\
\hline Ético & 9 & 2,33 & Alegria & 8 & 4,13 \\
\hline Paciência & 8 & 2,88 & Corajoso & 8 & 4,50 \\
\hline Respeito & 7 & 3,14 & Inovador & 8 & 3,25 \\
\hline- & - & - & Crítico & 7 & 3,86 \\
\hline- & - & - & Inteligente & 7 & 3,86 \\
\hline
\end{tabular}


Dos elementos constantes no quadrante de maior frequência e menor OME, ou de maior prontidão na memória dos informantes, estão os termos pesquisador, conscientização, curiosidade, vida, preservação, amor, compromisso e dedicação. $\mathrm{O}$ elemento pesquisador foi evocado por $76,09 \%$ dos informantes e teve uma OME menor, o que significa que foi evocado mais prontamente, fato esse que confirma sua centralidade. Entretanto, os demais elementos que fazem parte do grupo, mesmo compondo o núcleo central, têm uma posição hierárquica menor pela frequência e pela OME quando comparados a pesquisador.

A pesquisa é a principal atividade da formação do bacharel em Ciências Biológicas, sendo a centralidade da representação coerente com a qualificação e o exercício profissional, conforme prescreve o documento (RESOLUÇÃO CNE/ SESU, 2002) que rege a formação do biólogo. Porém, pelo fato de os participantes serem licenciandos, se esperava que algum dos elementos da docência também se fizesse presente no núcleo central.

Os elementos que aparecem nos quadrantes superior direito e inferior esquerdo fornecem suporte ao núcleo central, compondo os elementos intermediários da representação. Os elementos conhecimento, ético, respeito e compromisso remetem aos atributos do profissional cuja ferramenta de trabalho é a pesquisa. A presença do elemento professor é resultante da opção de atuação no mercado de trabalho, podendo ser justificada pelo fato de os licenciados em Ciências Biológicas também serem considerados biólogos. O elemento educador pode justificar a consciência sobre a responsabilidade desse profissional nos vários contextos de atuação profissional. Por sua vez, os elementos do quadrante inferior direito compõem a periferia mais distante; eles não são organizadores da representação, mas constituem particularidades que confirmam o indicativo da relação com pesquisador.

Para visualizar a organização da representação social de biólogo pelos licenciandos foi realizada uma análise de similitude, que contempla a conexidade dos elementos e as suas coocorrências. Para a formação da árvore de similitude, levou-se em consideração o mínimo de $5 \%$ de partilha das ocorrências.

Figura 2: Árvore Máxima de Similitude da representação social de "biólogo"

Fonte: Tolentino (2010, p. 68).

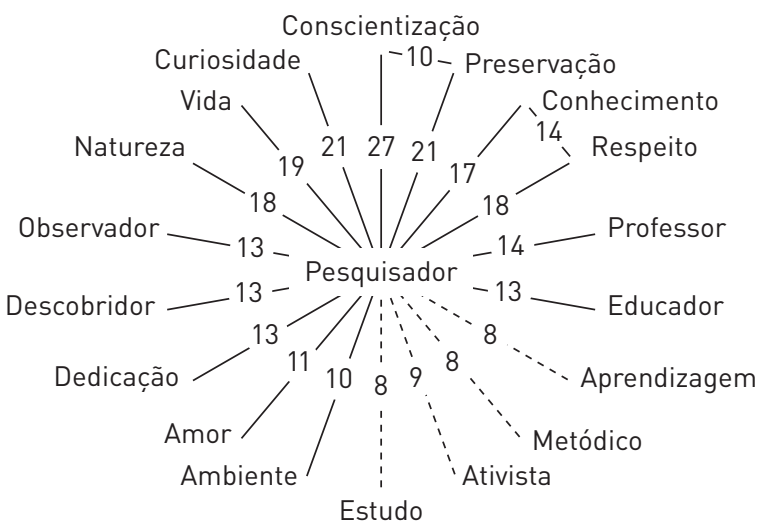


A análise de similitude dos licenciandos para a representação de biólogo aponta para a aglutinação dos termos em torno do elemento pesquisador, assegurando a função organizadora e estruturante do núcleo central. De acordo com Abric (2000), pode-se considerar a função normativa da representação social de biólogo "pelo sistema de valores e normas sociais que constituem o meio ambiente ideológico do momento e do grupo" (ABRIC, 2000, p. 31). O autor indica que não é somente a presença maciça do elemento que define sua centralidade, mas, sim, o fato de que é esse elemento que dá significado à representação. Para os licenciandos, o elemento pesquisador é central e uniu em torno de si os elementos mais significantes da representação; consideram que os elementos relativos à docência estão subordinados e não há conexão direta entre eles, como é o caso de professor, educador e aprendizagem.

Examinando a figura, é possível constatar a formação de dois triângulos: o primeiro deles é constituído pelos elementos pesquisador, conscientização e preservação; o segundo, pelos elementos pesquisador, conhecimento e respeito. Há uma forte conexidade no primeiro triângulo, principalmente na aresta de ligação entre pesquisador e preservação. O segundo triângulo evidencia a ideia da qualificação e da consideração ao trabalho desse profissional, usando-se para isso os elementos conhecimento e respeito. A conexidade relativamente forte com o elemento curiosidade reflete aspecto relativo a uma característica pessoal inerente ao ofício do pesquisador.

Por meio da análise das justificativas ${ }^{2}$ apresentadas ao elemento pesquisador, pode-se perceber que o termo se associa a conscientização, preservação, curiosidade, conbecimento e respeito. Conscientização e preservação parecem revelar a interface e o compromisso social da profissão do biólogo e ganhariam relevo à proporção que os problemas ambientais ganham a mídia.

"A curiosidade é a força motriz do início da biologia, de onde partiu toda a pesquisa e conhecimento científico." (Sujeito 57)

“[...] pesquisador, pois o biólogo está constantemente em contato com o ambiente, descobrindo novos conhecimentos e pesquisando." (Sujeito 89)

"Pesquisador é o que corre atrás do conhecimento para entender a vida e poder preservá-la corretamente." (Sujeito 91)

"O pesquisador deve ter curiosidade, pesquisar e ir em busca de novos conhecimentos." (Sujeito 99)

"[...] pesquisador por estar sempre em busca de alternativas que visem um mundo melhor, onde todos são beneficiados." (Sujeito 103)

"[...] biólogo é pesquisador e procura sempre formas de melhorar a qualidade de vida da população e do meio ambiente.” (Sujeito 131) 


\section{Análise das evocações à expressão indutora "professor é"}

A associação ao significado da expressão "professor é" produziu, com os 138 licenciandos participantes do estudo, um total de 753 palavras nas respostas, dentre as quais, 121 são termos diferentes. Para a composição dos elementos estruturais, foram desprezadas as evocações cuja frequência foi igual ou inferior a 7 (22,8\% do total). A constituição dos valores para a composição do núcleo central e de elementos periféricos foi extraída de relatório Rangmot emitido pelo software: frequência mínima $=7$, frequência intermediária $=23$ e OME $=3,3$.

$\mathrm{Na}$ figura a seguir, são apresentados os elementos oriundos das evocações:

Figura 3: Distribuição dos elementos da representação social de "professor".

Fonte: Tolentino $(2010$, p. 73).

\begin{tabular}{|c|c|c|c|c|c|}
\hline \multicolumn{3}{|c|}{ Núcleo central } & \multicolumn{3}{|c|}{ Elementos intermediários } \\
\hline \multicolumn{3}{|c|}{ Frequência $>=23, \mathrm{OME}<3,3$} & \multicolumn{3}{|c|}{ Frequência $>=23,0 M E>3,3$} \\
\hline Palavras & Freq. & OME & Palavras & Freq. & OME \\
\hline Educador & 71 & 2,18 & Amigo & 42 & 4,38 \\
\hline Conhecimento & 61 & 2,80 & Exemplo & 37 & 3,68 \\
\hline Pesquisador & 48 & 2,71 & Dedicação & 31 & 3,36 \\
\hline Ensino & 33 & 2,48 & Orientador & 28 & 3,50 \\
\hline Formador & 29 & 2,34 & Responsabilidade & 24 & 3,42 \\
\hline Aprendizagem & 23 & 2,83 & - & - & - \\
\hline \multicolumn{3}{|c|}{ Elementos Intermediários } & \multicolumn{3}{|c|}{ Periferia } \\
\hline \multicolumn{3}{|c|}{ Freq. $<23$, OME $<3,3$} & \multicolumn{3}{|c|}{ Freq. $<23, \mathrm{OME}>=3,3$} \\
\hline Palavras & Freq. & OME & Palavras & Freq. & OME \\
\hline Mestre & 17 & 2,65 & Aluno & 16 & 3,375 \\
\hline Compromisso & 14 & 2,64 & Motivação & 15 & 4,067 \\
\hline Humano & 13 & 2,92 & Compreensão & 11 & 3,636 \\
\hline Satisfação & 13 & 2,69 & Atento & 9 & 3,778 \\
\hline Criatividade & 7 & 3,29 & Autoridade & 9 & 3,778 \\
\hline Critico & 7 & 3,29 & Paciência & 9 & 4,889 \\
\hline- & - & - & Ético & 7 & 3,857 \\
\hline- & - & - & Inteligência & 7 & 4,143 \\
\hline
\end{tabular}

Os elementos considerados centrais na representação social de professor foram educador, conhecimento, pesquisador, ensino, formador e aprendizagem. Educador e conhecimento foram os elementos evocados com maior frequência, sendo que o primeiro deles obteve uma OME menor. Isso significa que a sua evocação ocorreu mais prontamente, o que confirma a sua provável centralidade. Os demais elementos que fazem parte do grupo, apesar de comporem o núcleo central, têm uma posição hierárquica menor, não sendo imprescindíveis à representação social de professor pelos licenciandos. 
Em relação a educador, há evidências de que os licenciandos compreendem professor e educador como sinônimos. Quando se busca nos dados o significado atribuído à palavra "educador", vê-se que grande parcela dos licenciandos associa ao educador a transmissão do conhecimento. É nesse sentido que se apresentam as falas dos sujeitos indicadas a seguir:

"Educador: passa o conhecimento que foi preparado para isso." (Sujeito 05)

"Educador: transmite conhecimento aos seus alunos." (Sujeito 20)

"Educador é aquele que ensina o necessário para que se formem pessoas com alto teor de conhecimento.” (Sujeito 21)

"Educador: porque o professor acima de qualquer característica tem que passar o seu conhecimento ao aluno." (Sujeito 25)

"Educador que transmite o conhecimento científico." (Sujeito 100)

No entanto, alguns licenciandos partilham do significado de educador como promotor de transformações na realidade de seus alunos. Verifica-se essa situação na fala de alguns sujeitos:

"Ser educador é passar conhecimento e coisas que são importantes para a formação do aluno, tanto formação escolar quanto formação de vida." (Sujeito 47)

"Não ensina e passa pro aluno apenas a matéria em si, mas também ensina a sermos uma pessoa melhor com personalidade e senso crítico.” (Sujeito 50)

"Além de passar o conhecimento, passa também lições de vida, educação." (Sujeito 59)

"Ser educador exige grande responsabilidade, pois o educador é o espelho do aluno e que abre seus olhos para o mundo.” (Sujeito 68)

"Educador é aquele que não apenas transmite conhecimento, mas que auxilia na formação de vida dos seus alunos." (Sujeito 89)

Pode-se dizer que a representação de professor pelos licenciandos foi construída historicamente, desenhada na socialização dentro do espaço escolar enquanto foram alunos, o que contribuiu para a noção que têm atualmente sobre o que é ser professor. De acordo com Abric (1994 citado por Sá, 1996), os elementos centrais permitem compreender a realidade vivida pelos indivíduos ou pelos grupos. Porém, o que se pôde perceber diante das duas concepções presentes para educador é que, de acordo com Bourdieu (2008), elas foram "comandadas pelas condições passadas da produção de seu princípio gerador" (BORDIEU, 2008, p. 84). Zeichner e Gore (1990 citados por Imbernón, 2000) ressaltam essa questão dizendo que alguns princípios da ação educativa são interiorizados durante a etapa 
escolar, em momentos e circunstâncias nos quais se assumem determinados esquemas ou imagens da docência. Nesse sentido, subentende-se que os licenciandos tiveram uma vivência diferente da relação professor-educador.

O domínio do conteúdo pelo professor é expresso a partir da evocação conhecimento. A esse respeito, Carvalho e Gil-Pérez (2006) ressaltam a importância do conhecimento da matéria a ser ensinada pelos professores de ciências. Já Kuenzer (1999) expõe que conhecer o conteúdo específico não basta, deve-se ter a capacidade de transpô-lo para situações educativas. Na verificação sobre o significado de "conhecimento" para os licenciandos, visualizou-se uma representação pragmática simbolizada pela transferência de conhecimento. Trazem-se abaixo algumas falas:

"Transmitir e compartilhar conhecimento é a principal função do professor." (Sujeito 29)

"Para passar informação aos alunos o professor necessita de conhecimento." (Sujeito 37)

"Saber repassar o conhecimento é fundamental, falar de forma clara, com que o aluno entenda." (Sujeito 44)

"É ele quem transmite o conhecimento dentro da sala de aula e por isso deve sempre estar bem-preparado." (Sujeito 87)

A centralidade do elemento pesquisador presente na representação do professor pressupõe um olhar à representação de biólogo. Levando-se em consideração que a pesquisa realizada pelo professor deve ser feita em torno dos eventos que envolvem a prática pedagógica e que a maioria dos licenciandos participantes da pesquisa ainda não havia se inserido no ambiente escolar ${ }^{3}$, não se pode consolidar um atributo de pesquisa como central na representação de professor.

A representação, como visão funcional do mundo, permite ao indivíduo ou ao grupo atribuir um sentido às condutas e compreender a realidade por meio do seu sistema de referências. Isso permite ao indivíduo a adaptação e o encontro de seu lugar nessa realidade, não como um simples reflexo, mas como uma organização significante, um guia para a ação, orientando as ações e as relações sociais (ABRIC, 2000). Diante disso, a ideia de pesquisador possui o mesmo significado que se dá para biólogo, que é a atividade cotidiana mais vivenciada pelos licenciandos, podendo-se considerar a presença desse elemento como um transporte do atributo à representação do professor, pois a docência será a principal habilitação profissional dos sujeitos após a conclusão do curso.

Para Deschamp e Moliner (2009), as representações sociais podem se tornar produtos identitários e instrumentos de afirmação de um grupo, organizando a percepção do espaço social em conveniência com as aspirações identitárias dos indivíduos. Tomando como orientação os pensamentos de Bourdieu, os autores sintetizam que "as condições objetivas de existência determinam os processos pelos quais se elaboram e se interiorizam as representações do social” (DESCHAMP; MOLINER, 2009, p. 111). A apropriação do elemento pesquisador revela as disposições 
circulantes no espaço social dos licenciandos, disposições duravelmente inculcadas que, pela presença central desse elemento, "engendram aspirações e práticas objetivamente compatíveis com as condições objetivas” (BOURDIEU, 2003, p. 56).

Dentre os elementos periféricos da representação, observa-se a associação dos atributos do professor à afetividade no trabalho pedagógico, por meio de expressões como dedicação, responsabilidade, amigo, exemplo, motivação, compreensão. Os elementos periféricos, mais associados ao contexto imediato no qual os indivíduos estão inseridos (ABRIC, 2000), podem ser considerados indicadores da importância para os licenciandos de desenvolver sua formação pautada em um componente afetivo. De acordo com Guareschi e Jovchelovitch (2003), a dimensão afetiva está presente na própria noção de representações sociais, juntamente com as dimensões cognitiva e social. Ribeiro et al. (2005) expressam que "a afetividade é impulsionada pela expressão dos sentimentos e das emoções e pode desenvolver-se por meio da formação" (RIBEIRO et al., 2005, p. 48)

A centralidade e a conexidade dos elementos que compõem a representação de professor pelos licenciandos são indicadas na análise de similitude ilustrada a seguir:

Figura 4: Árvore Máxima de Similitude da representação social de "professor" Fonte: Tolentino (2010, p. 76).

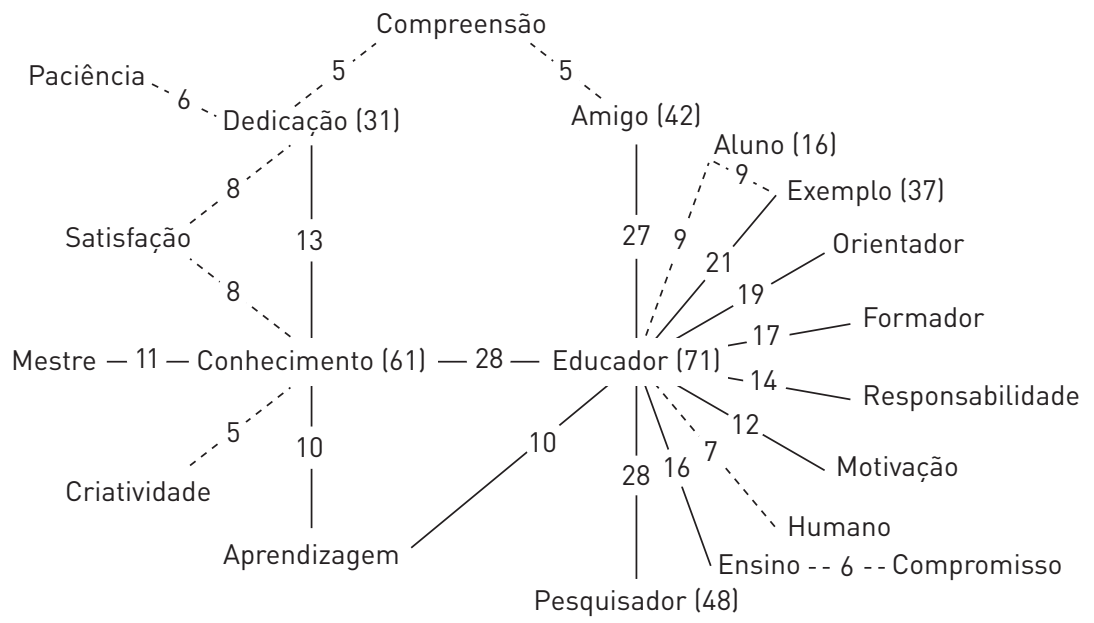

A análise da organização da representação social de professor afirma a centralidade dos elementos conhecimento e educador, sendo este o de maior poder associativo, com 12 arestas. Examinando a figura, constata-se a formação de um pentágono: educador, conhecimento, dedicação, compreensão e amigo; e, junto a esse pentágono, forma-se um triângulo com os elementos conhecimento, dedicação e satisfação. Formam-se também dois triângulos entre os elementos educador, aluno e exemplo; e educador, conbecimento e aprendizagem.

A formação do pentágono ilustra uma interação socioafetiva necessária para a apreensão do conhecimento, vista pela forte ligação do elemento educador 
com o elemento amigo. Tanto a ligação desses elementos (juntamente com a compreensão e a dedicação) como a projeção dessa figura por meio do triângulo que tem como vértice a satisfação ligada a dois elementos do pentágono são coerentes com a justificativa da análise dos elementos periféricos, que dão uma dimensão afetiva a essa representação social. De acordo com Sugahara e Souza (2010, s/n), "a afetividade é fator fundamental no trabalho docente, pois se apresenta não apenas como dimensão subjetiva do universo da docência, mas indica uma objetivação que se revela como forma de conhecimento".

O triângulo formado pelos elementos educador, exemplo e aluno apresenta uma forte ligação entre educador e exemplo, mostrando a figura do professor como exemplo, referência para o aluno, e que interfere diretamente na sua formação. As falas seguintes expressam esse sentido:

"O professor é referência porque os alunos passam boa parte de sua vida em contato com ele, assim é o professor que poderá formar cidadãos conscientes e muitas vezes até mudar a vida dos alunos." (Sujeito 18)

"É exemplo porque os seus alunos muitas vezes se espelham no professor, o que muitas vezes interfere na sua vida e até mesmo na escolha que pretende seguir.” (Sujeito 52)

"Modelo no sentido de que, na maioria dos casos, o aluno segue o exemplo do professor, acredita no que ele diz.” (Sujeito 55)

"Professor é exemplo primordial para o jovem. É o educador que confere ao aluno um senso crítico e estrutura boa parte do quadro moral e pessoal do aprendiz." (Sujeito 83) "O professor é exemplo que muitos alunos tentam seguir ou veneram, o professor é como se fosse parte da família do aluno, pois acompanha, orienta e vê o aluno crescer." (Sujeito 104)

"O professor é muitas vezes considerado exemplo para determinado aluno, professores são formadores de opinião." (Sujeito 138)

O triângulo formado pelos elementos educador, conhecimento e aprendizagem mostra a função da profissão na transmissão do saber, com a aprendizagem se constituindo como processo para aquisição de um conhecimento. O vínculo maior ilustrado na aresta educador-conhecimento aponta a centralidade da representação de professor pelos os licenciandos. Essa representação pode advir do processo formativo, que vai migrando das representações sociais mais antigas e arraigadas socialmente, como a expressão de cuidado e extensão do ambiente doméstico. De um educador centrado nas relações interpessoais passa-se a um educador profissional mediador das aprendizagens discentes.

O elemento pesquisador aparece vinculado ao educador, não sendo, então, central na representação de professor. Aquele elemento não possui vínculo algum com nenhum outro elemento, o que pressupõe que essa representação seja uma produção simbólica que, à luz da noção de habitus, advém das disposições interiorizadas pelos licenciandos diante das condições objetivas presentes no 
curso. Apesar de expressar uma forte ligação com o termo educador, não possui elementos capazes de lhe dar circularidade, como no caso do pentágono educador-conhecimento-amigo-dedicação-compreensão e nos casos dos triângulos educadorconhecimento-aprendizagem e educador-exemplo-aluno.

\section{CONSIDERACְÕES FINAIS}

O presente trabalho objetivou explicitar quais representações sobre biólogo e professor estão em evidência para licenciandos de Ciências Biológicas de uma universidade pública estadual situada no Estado do Paraná. Problematizou-se se as representações apresentadas são influenciadas pelos meios social e ideológico em que os licenciandos estão imersos.

A análise das informações obtidas foi subsidiada pela Teoria das Representações Sociais, de Serge Moscovici (2003), relacionando-a com o conceito de habitus de Pierre Bourdieu (1997, 1999, 2003, 2009). Tal articulação teórica mostra a possibilidade desses referenciais na produção de resultados sobre a compreensão do processo de constituição da docência durante um curso de formação inicial de professores.

Dentro dessa perspectiva, o curso de Licenciatura em Ciências Biológicas foi visto como espaço social, uma vez que, ao atuar como responsável pela formação profissional do professor de ciências e biologia, produz valores e referências durante o processo formativo. Tais valores são expressos nas disposições (babitus) dos indivíduos, que mobilizam estruturas cognitivas por meio das quais são representados esse universo e seus objetos.

Por meio da análise do núcleo central das representações de professor e biólogo, foi possível perceber que a concepção dos licenciandos em relação ao biólogo é homogênea, com a centralidade única no elemento pesquisador e todos os outros elementos da representação se ligando a tal elemento. Conjugam-se as certezas sobre o que o outro representa, juntamente com suas atribuições sociais e morais. Certezas que são reafirmadas nas rotinas e nas práticas do processo formativo e se estruturam cognitivamente nos licenciandos. Quanto à representação de professor, tiveram-se as evocações dos licenciandos como uma construção histórica bastante arraigada na trajetória escolar, evidenciando a formação ambiental durante o período em que foram alunos (CARVALHO; GIL-PÉREZ, 2006). Esse ponto reafirma as considerações de Abric (2000) no que diz respeito à constituição da centralidade de uma representação, que é ligada às condições históricas, com determinação essencialmente social.

Os componentes afetivos expressos no sistema periférico da representação de professor revelam uma visão romântica e abstrata de um educador centrado nas relações interpessoais. Esses componentes são importantes para o exercício profissional, porém, insuficientes. Como o sistema periférico indica a ancoragem da representação na realidade, presume-se que os elementos constitutivos da docência 
não se apresentam de forma efetiva no cotidiano e nas práticas do ambiente formativo. O que se destaca nessa representação é o transporte do elemento pesquisador à representação do professor, o que revela as disposições circulantes no espaço social dos licenciandos, situação essa que corrobora outros achados sobre a formação dos professores de ciências e biologia carecer de referencial específico voltado à formação de professores (BRANDO; CALDEIRA, 2009; ROSSO, 2007; GATTTI, 2010).

Ao se evidenciar que a área de conhecimento biológico atinge uma maior centralidade na licenciatura, considera-se que a construção da identidade da docência é secundada. Há uma diferença, que não é apenas de caráter semântico, entre a formação do professor de biologia e a do biólogo professor. Não se trata apenas de uma inversão entre substantivos e adjetivos, mas da prática desenvolvida no processo formativo, a qual é dirigida a partir da área de conhecimento, e não da docência. Isso favorece a hipótese de que o habitus desenvolvido no curso não altera substancialmente essa tendência.

As evocações dos licenciandos sobre o biólogo e sobre o professor expressam os elementos circulantes em seu espaço social, os quais legitimam as posições hierarquizadas do conhecimento biológico e do conhecimento educacional e a fragilidade epistemológica e conceitual do conhecimento educacional no cotidiano das práticas da licenciatura. O habitus resulta do modo como o meio social se materializa nos indivíduos, funcionando como "uma matriz de percepções, de apreciações e de ações” (BOURDIEU, 2003, p. 57). A função de orientação das representações sociais (ABRIC, 2000) guia comportamentos e práticas; e, ao mesmo tempo, silencia ou põe na periferia os atores, os espaços e os elementos centrais da docência, como o aluno, a sala de aula e a escola.

Trata-se de representações advindas da "formação ambiental", cujo resultado previsto é a sua reprodução de forma tácita nas atividades profissionais, por se constituírem na "continuidade de uma mesma atividade profissional" (MALDANER, 1998, p. 201), o que acaba reforçando o mesmo modo de prática. O desafio aos docentes formadores que atuam nas ciências biológicas está em pensar além das especificidades do conhecimento biológico, atuando segundo os princípios de uma "ecologia formativa" (ROSSO, 2007) capaz de integrar o conjunto de rotinas com os objetos da docência e estabelecer intencionalidade e consciência coletiva, de fundamental importância para a construção da identidade profissional do professor de ciências e biologia.

\section{NOTAS}

${ }^{1} \mathrm{O}$ parâmetro a ser considerado como modelo dentro do processo formativo é o da formação profissional bacharelado, devido ao fato de sua atuação profissional voltada à pesquisa servir como base 
de identificação com as Ciências Biológicas. Neste trabalho, o profissional que tem essa formação é denominado "biólogo", sabendo-se que o licenciado também pode possuir essa denominação.

2 As justificativas apresentam as respostas dos sujeitos da pesquisa, vinculada à associação livre de palavras mencionada na descrição da metodologia. Para preservação do anonimato, os sujeitos participantes foram codificados em ordem numérica.

${ }^{3} \mathrm{~A}$ inserção dos licenciandos no ambiente escolar, na instituição estudada, inicia-se a partir do $3^{\circ}$ ano do curso, com a disciplina Estágio Curricular Supervisionado I.

\section{REFERÊNCIAS}

ABRIC, J. C. A abordagem estrutural das Representações Sociais. In: MOREIRA, A. S. P.; OLIVEIRA, D. C. (Org.). Estudos interdisciplinares de representação social. Goiânia: AB Editora, 2000.

ACOSTA, S. F.; et al. Trabalho docente na ótica de universitários ingressantes. In: REUNIÃO ANUAL DA ASSOCIAÇÃO NACIONAL DE PÓS-GRADUAÇÃO E PESQUISA EM EDUCAÇÃO, 30., 2007, Caxambu. Anais... Caxambu: ANPED, 2007.

ALVES-MAZZOTTI, A. J. Representações da identidade docente: uma contribuição para a formulação de políticas. Ensaio: Avaliação em políticas públicas, Rio de Janeiro, v. 15, n. 57, p. 579-574, Out/Dez 2007.

ANDRADE, E. P. et al. A dimensão prática na formação inicial docente em Ciências Biológicas e em História: Modelos formativos em disputa. Ensino em Re-Vista, Uberlândia, n. 12, v. 1, p. 7-21, jul/2004.

BERGER, P.; LUCKMANN, T. A Construção Social da Realidade. Petrópolis: Vozes, 2004.

BONNEWITZ, P. Primeiras lições sobre a sociologia de P. Bourdieu. Petrópolis: Vozes, 2003.

BOURDIEU, P. Razões práticas: sobre a teoria da ação. Campinas: Papirus, 1997. . Coisas Ditas. São Paulo: Brasiliense, 1999.

. Esboço de uma teoria da prática. In: ORTIZ, R.(Org.) A Sociologia de Pierre Bourdieu. São Paulo: Olho d'Água, 2003. p. 39-72,

. Futuro de classe e causalidade do provável. In: NOGUEIRA, M. A.; CATANI, A. (Orgs.)

Escritos de educação. Petrópolis: Vozes, 2008.

. O senso prático. Petrópolis: Vozes, 2009.

BRANDO, F. R.; CALDEIRA, A. M. A. Investigação sobre a identidade profissional em alunos de Licenciatura em Ciências Biológicas. Ciência e Educação, São Paulo v. 15, n. $1,2009$.

BRASIL, MEC/CNE. Resolução CNE/CP 1/2002a- Diretrizes Curriculares Nacionais para a Formação de Professores da Educação Básica, em nível superior, curso de licenciatura, de graduação plena. 2002. Disponível em: < http://portal.mec.gov.br/cne/arquivos/pdf/CP0 12002.pdf.> Acesso em: 23 mar. 2013.

BRZEZINSKI, I. Pedagogia, pedagogos e formação de professores. Campinas: Papiros, 1996.

CANDAU, V. M. F. Universidade e formação de professores: Que rumos tomar? In: (Org.) Magistério, construção cotidiana. Petrópolis: Vozes, 1997.

CANDAU, V. M. F.; LELIS, I. A. A relação teoria-prática na formação do educador. In: CANDAU, V. M. F. (Org.). Rumo a uma nova didática. 9. ed. Petrópolis: Vozes, 1999, p. 56-72.

CARVALHO, A. M. P.; VIANNA, D. A quem cabe a licenciatura. Ciência e Cultura, Campinas, v. 40, n. 2, p. 143-47, 1988.

CARVAlHO, A. M. P.; GIL-PÉREZ, D. Formação de Professores de Ciências: tendências e inovações. 
São Paulo: Cortez, 2006.

CUCHE, D. O Conceito de Cultura nas Ciências Sociais. Bauru: EDUSC, 2002.

DESCHAMPS, J. C.; MOLINER, P. A identidade em Psicologia Social: Dos processos identitários às representações sociais. Petrópolis: Vozes, 2009.

DINIZ-PEREIRA, J. E. As Licenciaturas e as novas políticas educacionais para formação docente. Educação \& Sociedade, Campinas, n. 68, p. 109-125, 1999.

. Formação de professores: Pesquisas, representações e poder. Belo Horizonte: Autêntica, 2000.

DOISE, W. Da Psicologia Social à Psicologia Societal. Psicologia: Teoria e Pesquisa, v. 18, n. 1, p. 27-35, 2002.

FREITAS, D.; VILLANI, A. Formação de professores de ciências: um desafio sem limites. Investigações em Ensino de Ciências, Porto Alegre, v. 7, n. 3, 2002.

GATTI, B. A formação dos docentes: O confronto necessário professor x academia. Cadernos de Pesquisa, n. 81, p. 70-74, 1992.

. Formação de professores e carreira: problemas e movimentos de renovação. Campinas: Autores Associados, 2000.

Formação de professores no Brasil: características e problemas. Educação e Sociedade, v. 31, n. 113, out/dez 2010 .

GUARESCHI, P.; JOVCHELOVITCH, S. (Orgs.) Introdução. Textos em representações sociais. Petrópolis: Vozes, 2003.

IBERNÓN, F. Formação docente e profissional: formar-se para a mudança e a incerteza. São Paulo: Cortez, 2000.

JODELET, D. Representações Sociais: Um domínio em Expansão. In: (Org.) As Representações Sociais. Rio de Janeiro: EdUERJ, 2001.

KUENZER, A. As políticas de formação: A constituição da identidade do professor sobrante. Educação e Sociedade, São Paulo, n. 68, p. 163-183, dez/1999.

LUDKE, M. Formação de docentes para o ensino fundamental e médio: As Licenciaturas. Rio de Janeiro: CRUB, 1994.

MALDANER, O. A. A necessária conjugação da pesquisa e do ensino na formação de professores e professoras. In: CHASSOT, A.; OLIVEIRA, R. Ciência, ética e cultura na educação. São Leopoldo: Ed. Unisinos, 1998, p. 193-214.

MELLO, G. N. Formação inicial de professores para Educação Básica: uma (re)visão radical. São Paulo em Perspectiva, n. 14, v. 1, 2000.

MOSCOVICI, S. Representações Sociais: Investigações em Psicologia Social. Petrópolis: Vozes, 2003

PIMENTA, S. G. O estágio na formação de professores: unidade teoria e prática? São Paulo: Cortez, 1994.

RESOLUÇÃO CNE/SESU 07/02, de 11 de março de 2002. Estabelece as Diretrizes Curriculares para os Cursos de Ciências Biológicas. Disponível em: <http://portal.mec.gov.br/cne/arquivos/ pdf/rces07_02.pdf>. Acesso em: 19 mar. 2013.

RIBEIRO, M. L. et al. Análise das representações sociais da afetividade na relação educativa. Psicologia da Educação, São Paulo, n. 20, p. 31-54, jun/2005.

ROSSO, A. J. Avaliação dos significados atribuídos pelos estagiários à Metodologia e Prática de Ensino de Biologia. Práxis Educativa, Ponta Grossa, v. 2, n. 2, 2007.

SÁ, C. P. Núcleo central das representacooes sociais. Petrópolis: Vozes, 1996.

SAVIANI, D. Formação de professores: aspectos históricos e teóricos do problema no contexto brasileiro. Revista Brasileira de Educação, v. 14, n. 40, jan/abr 2009.

SETTON, M. G. J. A socialização como fato social total: notas introdutórias sobre a teoria do habitus. Revista Brasileira de Educação, São Paulo, v. 14, n. 41, 2009.

SPINK, M. J. Desvendando as teorias implícitas: uma metodologia de análise das Representações Sociais. In: Guareschi, P. A.; Jovchelovitch, S. (Org.) Textos em Representações Sociais, Petrópolis: 
Vozes, 1995.

SUGAHARA, L. Y.; SOUZA, C. P. A dimensão afetiva nas representações sociais sobre o trabalho docente. In: REUNIÃO ANUAL DA ASSOCIAÇÃO NACIONAL DE PÓS-GRADUAÇÃO E PESQUISA EM EDUCAÇÃO, 33., 2010, Caxambu. Anais... Caxambu: ANPED, 2010.

TOLENTINO, P. C. As referências da formação inicial na representação dos licenciandos em Ciências Biológicas da Universidade Estadual de Ponta Grossa. 2010. 177 f. Dissertação (Mestrado em Educação) Universidade Estadual de Ponta Grossa, Ponta Grossa, 2010.

VILLANI, A.; PACCA, J. L. A.; FREITAS, D. Formação do professor de Ciências no Brasil: tarefa impossível? In: ENCONTRO DE PESQUISA EM ENSINO DE FÍSICA, Águas de Lindóia, Sociedade Brasileira de Ensino de Física. Anais... Águas de Lindóia: SBEF, 2002.

Data Recebimento: 19/05/2013

Data Aprovação: 12/10/2014

Data Versão Final: 11/11/2014

Contato:

Patricia Caldeira Tolentino

Universidade Estadual de Ponta Grossa, Reitoria, Núcleo de Tecnologia e Educação Aberta e a Distância. Universidade Estadual de Ponta Grossa - Campus Uvaranas

Uvaranas - Ponta Grossa, PR - Brasil- CEP: 84030900.

Email: pctolentino@uepg.br 